Available online at www.eccomasproceedia.org

Eccomas Proceedia COMPDYN (2021) 3697-3719

ECCOMAS

Proceedia
COMPDYN 2021

$8^{\text {th }}$ ECCOMAS Thematic Conference on Computational Methods in Structural Dynamics and Earthquake Engineering M. Papadrakakis, M. Fragiadakis (eds.) Streamed from Athens, Greece, 28 - 30 June 2021

\title{
LONG TERM MONITORING OF THE SANTA MARIA DI COLLEMAGGIO BASILICA
}

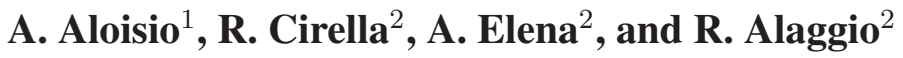 \\ 1 e-mail: angelo.aloisio1@uni vaq.it \\ 2 e-mail: \{riccardo.cirella, elena.antonacci, rocco.alaggio\}@univaq.it
}

\begin{abstract}
The Santa Maria di Collemaggio basilica is a 13th-century masonry masterpiece. The restoration works following the 2009 earthquake in L'Aquila included the installation of a permanent monitoring system. Crack gauges monitor a few significant cracks that appeared during the 2009 earthquake. Force-Balance accelerometers record the dynamic response of the entire structure. The dynamic response to ambient excitation leads to the estimation of the modal parameters. The current paper reports the outcomes of two years of static and dynamic monitoring from 1/1/2018 to 31/12/2019. The authors correlated the outdoor temperature and relative humidity to both the amplitude of the cracks and the modal parameters. The temperature deeply affects the static and dynamic response of the basilica. However, the linear correlations between the temperature and the structural response are diverse. There are cracks which stretch when the temperature rises and cracks which act oppositely. Natural frequencies lower when the temperature rises, while the same modes exhibit modal interaction phenomena. Furthermore, the natural frequencies of the basilica are not stationary but are moderately declining across the years. The basilica is a complex structure, where the different constitutive behaviour of three different materials, masonry, steel and timber may yield a varied structural response. The authors attempt to provide a qualitative interpretation of the observed behaviour, namely the detected correlations to the outdoor temperature, the lowering of the natural frequencies across the years and mode interaction phenomena.
\end{abstract}

Keywords: Structural Heath Monitoring; Automatic Operational Modal Analysis; Environmental effects; Static monitoring; Frequency veering. 


\section{INTRODUCTION}

Long term monitoring of civil structures belongs to almost thirty years of practice $[1,2,3]$. However, the long term monitoring of large masonry structures has almost ten years of history. After the work by Ramos et al. [4], a few other scholars investigated the static and dynamic behaviour of historical masonry structures: towers [5, 6, 7], cathedrals [4] and palaces [8].

A few research groups, mainly concentrated in the Mediterranean area, dedicated their research efforts to this topic. Concerning the masonry churches, L.F. Ramos et al. [4] and Masciotta et al. [9, 10] monitored the Church of Monastery of Jeronimos. Elyamani et al. [11] monitored the Mallorca cathedral (Mallorca Island, Spain) under ambient sources of vibration and seismic events. A few monthsago, Gentile et al. [12] reported on the long-term monitoringof the Milan cathedral, which hosts the most extensive monitoringsystem ever installed in a cultural heritage monument.

The current paper illustrates the static and dynamic monitoring of the Santa Maria di Collemaggio basilica. Differently from the considered cases, the Church of Monastery of Jeronimos, the Mallorca cathedral and the Milan cathedral, the Santa Maria di Collemaggio basilica suffered the structural consequences of a destructive earthquake in 2009. The monitoring system will allow understanding, not just the correlation of the modal parameters to environmental effects, but the effects of the retrofittin interventions.

The University of L'Aquila began the study of the dynamics of the Santa Maria di Collemaggio basilica in 1989. Dozens of scholars studied the basilica from historical [13], archaeological [14], architectural $[15,16,17,18]$, structural $[19,20,21,22,23,24,3,25,26,27]$, geotechnical $[28,29]$ and even energetic [30] perspectives. The dynamics of the Basilica was investigated by the University of L'Aquila $[31,32,33,34,35,36]$. So far, no study presented the results of long-term monitoring of the Santa Maria di Collemaggio basilica.

After the 2009 earthquake in L'Aquila, the University of L'Aquila, the University La Sapienza in Rome and the Politecnico in Milan supported the design phase of the restoration, supervised by the Soprintendenza ai Beni Architettonici e Paesaggistici per l'Abruzzo. A funding agreement, signed by Eni and the municipality of L'Aquila, pointed at developing a paradigmatic model in the panorama of restoration of monumentalarchitectural heritage, based on a multidisciplinary plan. The University of L'Aquila was further commissioned to conceive a monitoring system, which could operate during and after the rehabilitation. In the firs working phase, the monitoring system provided the construction manager with a survey tool about structural interventions. After the rehabilitation, the monitoringsystem was fully-fledge an essential instrumentfor the implementation of the conservation plan. The conservation plan aims at assessing the conservation state of the basilica, based on its intrinsic vulnerability and the regional seismic risk.

Moreover, the permanent monitoring system, installed in 2017, aims at supporting research activities which will possibly lead to the assessment of reliability thresholds, damage detection and damage localization. The significan number of accelerometers allows a refine resolution of the mode shapes and may give enough information to reliably estimate the evolution of the structuralcondition of the basilica, especially after seismic events. The definitio of the reliability thresholds is essential in assessing the structural safety based on dynamic data after seismic events.

The paper presents selected results from the long-term monitoringof the Santa Maria di Collemaggio basilica extracted from [37]. 


\section{The basilica}

Santa Maria di Collemaggio, built at the end of the 13th century, is a large medieval church in L'Aquila, central Italy. It is a world-famous church for its significanc in religious history [38]. The elegant Romanesque façade has the appearance of a wall, with a central door, embellished in the 15th century, and two smaller flankin doors; The interior follows the standard plan of a nave and two side aisles, each one divided from it by a row of columns, from which arches supporta tall wooden ceiling. The Basilica has a masonry structure typical of ancient buildings in L'Aquila [39], with varied, but prevalently regular, masonry textures [38, 40, 41, 42]. On the lateral wall stands the Holy Door (Fig.1(c)), opened on 28th and 29th of August every year in occasion of the annual jubilee.

The Basilica has a middle nave (61 m long and $11.3 \mathrm{~m}$ wide) and two side naves (approx $8 \mathrm{~m}$ wide). The central and side naves reach a maximum height of $20.4 \mathrm{~m}$ and $15 \mathrm{~m}$ respectively, while the facade is $29.5 \mathrm{~m}$ wide and $21.3 \mathrm{~m}$ high.

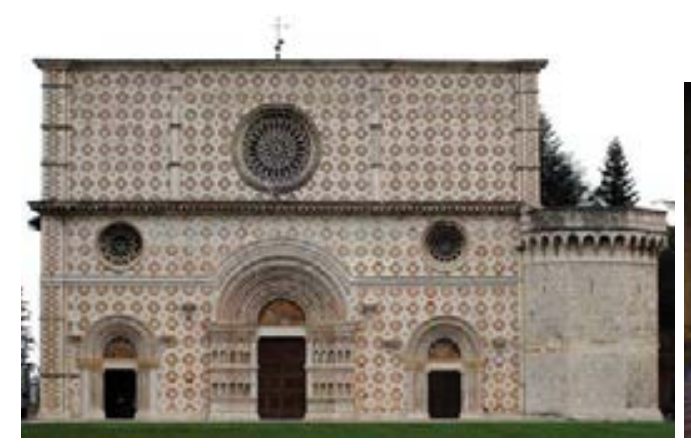

(a)

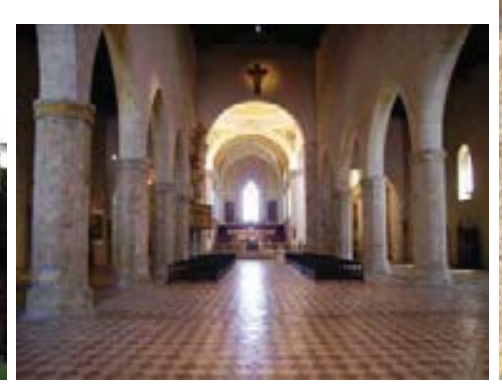

(b)

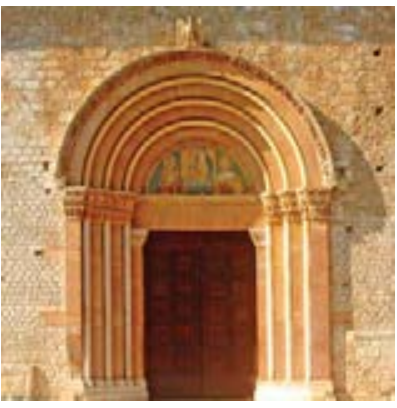

(c)

Figure 1: (a) Facade, (b) interior, (c) Holy Door, (d) plan of the basilica, (e) prospect of the apse, (f) and the Holy Door wall.

The permanent monitoring system consists of nine crack measurement devices, 78 Forcebalance accelerometers ( 2 triaxial 12 biaxial and 48 monoaxial), and f ve temperature/humidity sensors.

The crack measurement devices are high precision triangulation lasers with a $25 \mathrm{~mm}$ measuring range, $0.03 \mathrm{~mm}$ linearity and $2.5 \mu \mathrm{m}$ reproducibility. The FBA accelerometers are characterized by a $2.5 \mathrm{~V} / \mathrm{g}$ sensitivity. The details of the monitoring system are presented in [37]

\section{Long term static monitoring}

The monitoring devices, placed over significan cracks, have acquired every hour since $31 / 08 / 2018$. The authors report selected results from $31 / 08 / 2018$ to $21 / 12 / 2019$. The behaviour of the cracks suggests the following coarse classification see Tab.1:

- FP2, FP3 and FP7 (Fig.2(b),(c),(g)): The amplitude is almost constant with oscillation between the maximum and minimum amplitudes equal to $0.03 \mathrm{~mm}, 0.04 \mathrm{~mm}$ and 0.0 $6 \mathrm{~mm}$ respectively.

FP2 and FP7 are the sole devices which monitor the cracks on the intrados of the ogival arches in the central nave. The amplitude rests constant, likely meaning that the ogival arches are stable against static forces and environmental parameters. FP3 reveals the stability of a crack below a pavilion vault on the right side of the apse. 
Table 1: Statistical description of the amplitude of the instrumentedcracks from 31/08/2018 to 21/12/2019

\begin{tabular}{ccccc} 
Instrument & \multicolumn{4}{c}{ Crack measurement $[\mathrm{mm}]$} \\
& Mean & Variance & Maximum & Minimum \\
\hline FP1 & 0.11 & $7.50 \times 10^{-4}$ & 0.18 & 0.06 \\
FP2 & 0.07 & $9.10 \times 10^{-5}$ & 0.09 & 0.06 \\
FP3 & 15.68 & $3.67 \times 10^{-5}$ & 15.69 & 15.65 \\
FP4 & 0.71 & $5.15 \times 10^{-3}$ & 0.86 & 0.57 \\
FP5 & 1.02 & $9.00 \times 10^{-3}$ & 1.17 & 0.81 \\
FP6 & 0.10 & $5.21 \times 10^{-4}$ & 0.16 & 0.06 \\
FP7 & 5.73 & $1.88 \times 10^{-4}$ & 5.75 & 5.69 \\
FP8 & 0.22 & $1.34 \times 10^{-3}$ & 0.31 & 0.16 \\
FP8 & 6.19 & $1.99 \times 10^{-2}$ & 6.42 & 6.18
\end{tabular}

- FP1, FP4, FP6, FP8 and FP9 (Fig.2(a),(d),(f),(h),(i)) show higher discrepancies between the minimum and maximum amplitudes, equal to $0.12 \mathrm{~mm}, 0.29 \mathrm{~mm}, 0.10 \mathrm{~mm}$ and 0.24 mm respectively. The amplitude of these cracks increases during spring and summer and decreases in the cold seasons. These devices measure the amplitude of the cracks in the presbiterion: the right chapel (FP4 and FP8), the apse (FP5, FP8 and FP9) and the left chapel (FP1).

- FP5 (Fig.2(e)) yields a $0.36 \mathrm{~mm}$ discrepancy between the two extreme values. However, the amplitude decreases during the cold season and vice versa. FP5 monitors a crack on the intrados of the apse vault.

\subsection{Environmental effects}

The evolution of the amplitudes suggests a season-driven behaviour: the environmental parameters mainly determine the observed oscillations. Unfortunatdy, the thermoigrometerssuffered functioning discontinuities due to the difficult in promptly replacing the batteries by the owner of the basilica. For this reason, the authors adopted as correlation parameters the outdoor temperature and relative humidity recorded by the CETEMPS, (the Centre of Excellence on Telesensing of Environmentand Model Prediction Severe events, see http://cetemps.aquila.infn.it/) in L'Aquila. Fig.3(a)-(b) show the minute by minute evolution of the temperature and relative humidity from $1 / 1 / 2018$ to $31 / 12 / 2019$. The relative humidity has a scattered behaviour; a red line follows the averaged trend obtained from a moving average over a thousand samples. Fig.4 illustrates the correlation between the crack amplitudes and the temperature. The correlations to temperatureconfir three trends, already remarked in the previous paragraphs. (i) An almost stationary behaviour in FP2, FP3 and FP7; (ii) A positive rate in FP1, FP4, FP6, FP8 and FP9; (iii) A negative rate in FP5.

The two opposite trends may descend from opposing kinematic mechanisms, which can determine the closing or stretching of the cracks when the masonry swells from thermal expansion. Except for FP9, which is placed outside the apse, the other devices are inside the basilica. Two kinematic mechanisms may stand behind the identifie correlations.

The temperature is not constant across the wall thickness. During summer, the outer layers have higher temperature values than the inside ones, and vice versa during winter: likely, a $15^{\circ} \mathrm{C}$ temperature difference between the outer and inner wall layers occurs during summer and an opposite $15^{\circ} \mathrm{C}$ difference during winter. The thermal gradient may yield the curvature of the wall, see Fig.5: the external crack stretches $\left(l_{1}\right)$, while the internal one reduces $\left(l_{2}\right)$. By assuming a thermal expansion coefficien equal to $\alpha=5 \times 10^{-6}\left[{ }^{\circ} \mathrm{C}^{-1}\right]$, and a $\Delta T=30^{\circ} \mathrm{C}$ gradient, 


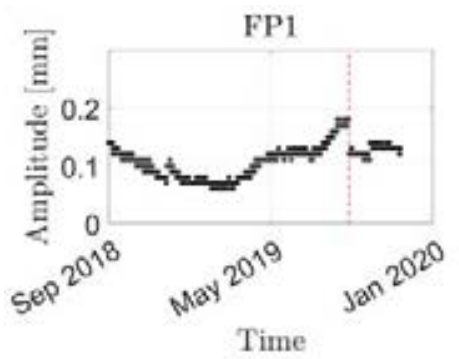

(a)

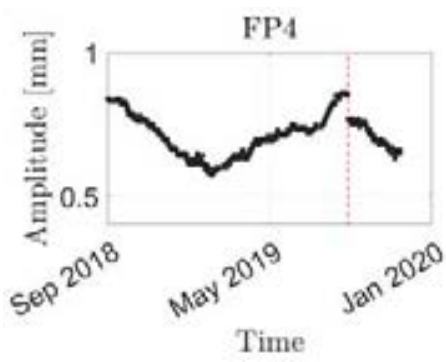

(d)

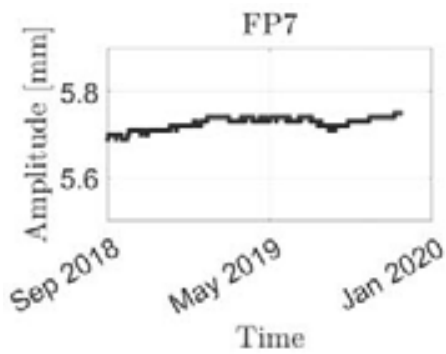

(g)

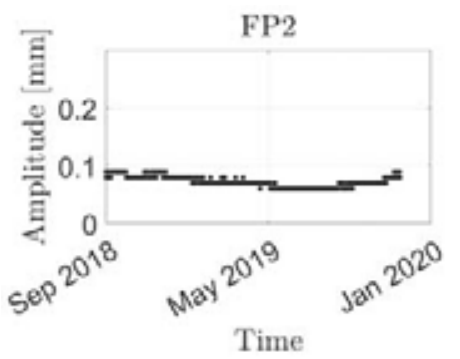

(b)

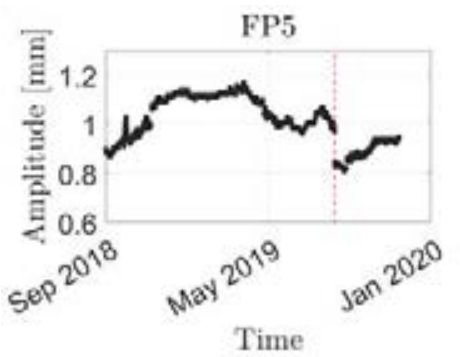

(e)

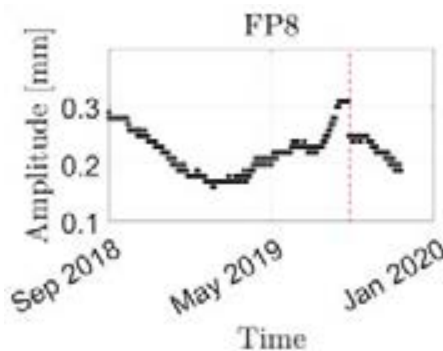

(h)

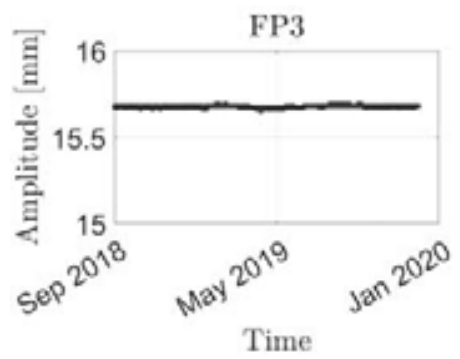

(c)

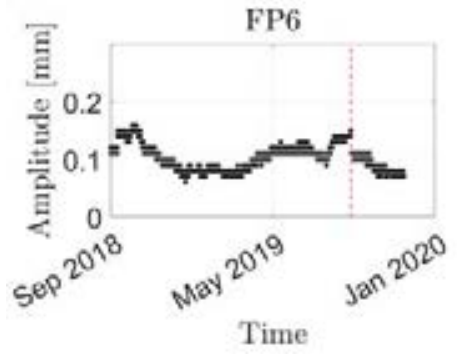

(f)

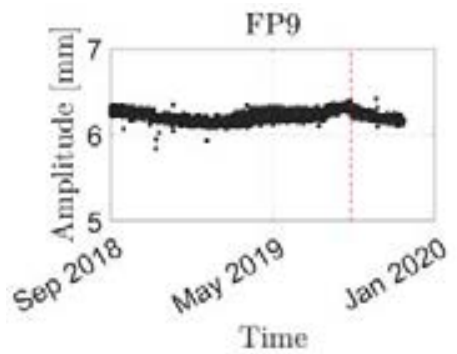

(i)

Figure 2: Variation of the cracks amplitudes measured from 31/08/2018 to 21/12/2019. The drops in FP1, FP4, FP5 and FP8 derive from almost one month interruption,indicated by a dashed vertical line.

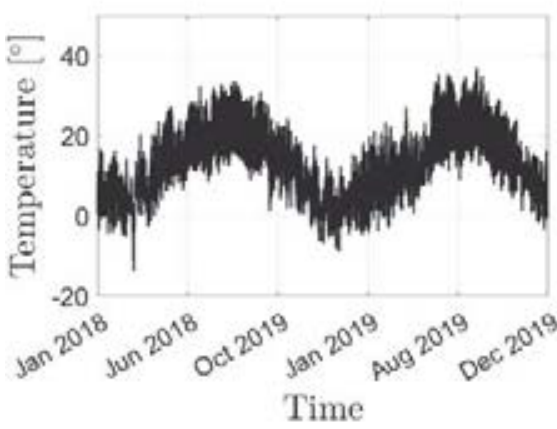

(a)

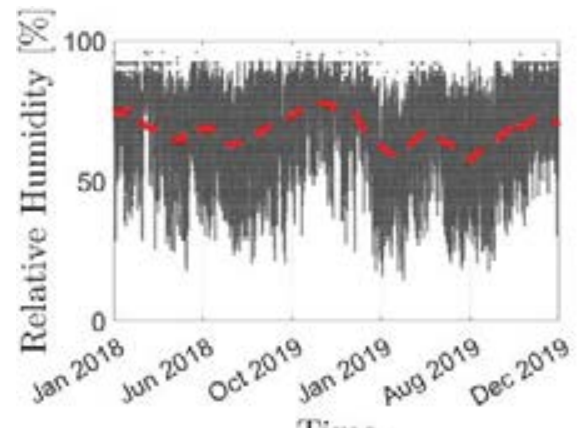

Time

(b)

Figure 3: Variation of the environmental parameters measured from 1/01/2018 to 31/12/2019: (a) Outdoortemperature; (b) Outdoor Relative Humidity; The red line is the moving average over a thousand samples. 


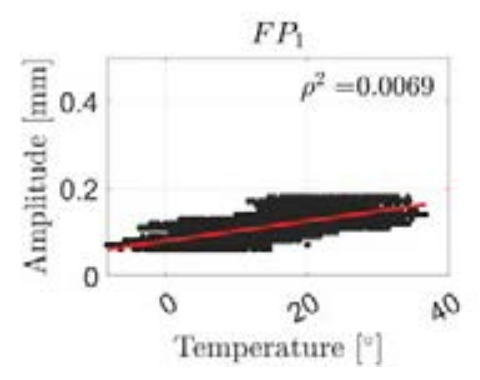

(a)

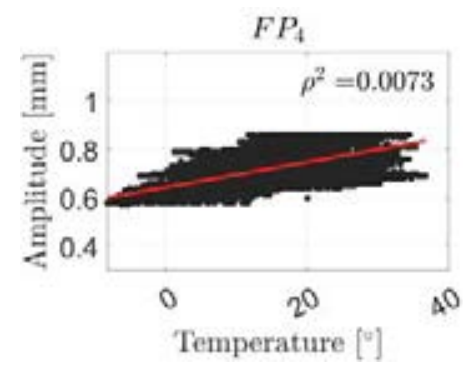

(d)

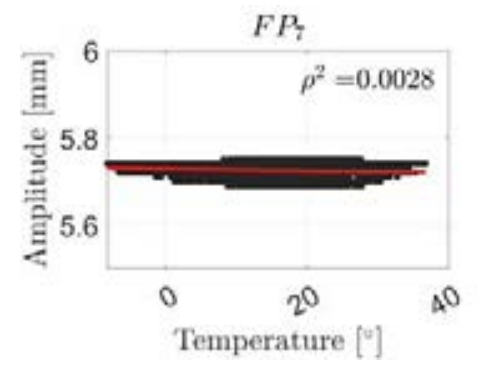

(g)

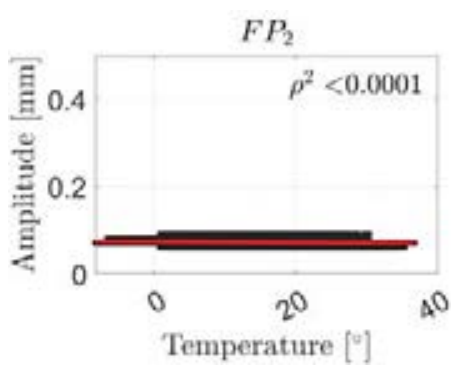

(b)

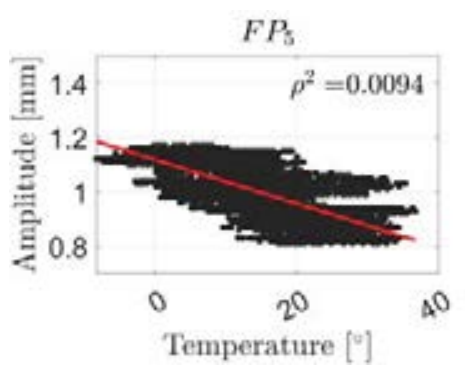

(e)

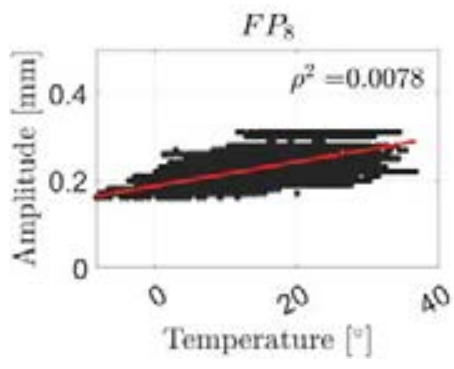

(h)

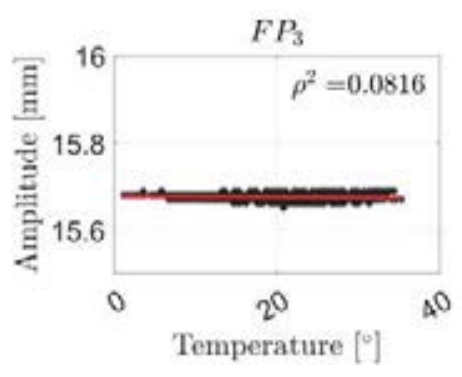

(c)

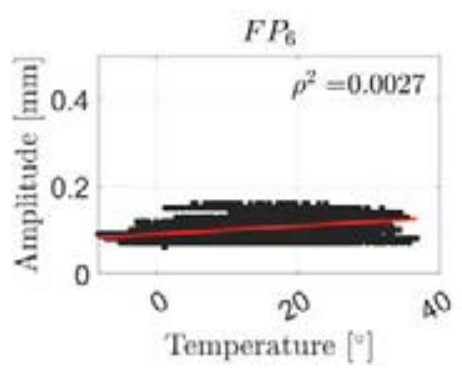

(f)

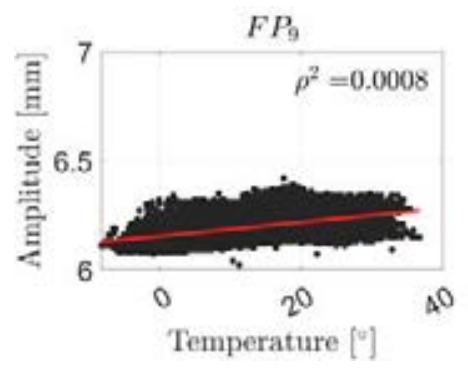

(i)

Figure 4: Correlation between the crack amplitude and the outdoor temperature (from 31/08/2018 to 21/12/2019). 
obtained by summing the absolute gradients of summer $\left(\Delta T_{s}=15^{\circ} \mathrm{C}\right)$ and winter $\left(\Delta T_{w}=-15^{\circ} \mathrm{C}\right)$, the equivalent thickness $t_{e q}$ associated to the maximum drifts are approximately between $0.8 \mathrm{~m}$ and $2 \mathrm{~m}$, see Tab.2, according to the following equations:

$$
\begin{gathered}
|\Delta x|_{\max }=\left|\Delta x_{s}\right|+\left|\Delta x_{w}\right|=t_{e q} \alpha\left(\left|\Delta T_{s}\right|+\left|\Delta T_{w}\right|\right) \\
t_{e q}=\frac{\Delta x_{\max }}{\alpha \Delta T}
\end{gathered}
$$

where $t_{e q}$ is the equivalent thickness, $\Delta x_{\max }$ the relative movement of the crack during the year, obtained by summing the effects of summer $\Delta x_{s}$ and winter $\Delta x_{w}, \alpha$ the thermal expansion coefficien and $\Delta T$ difference between the outdoor temperature during summer and the indoor temperature during winter. Tab. 2 reports the equivalent thickness related to the devices which

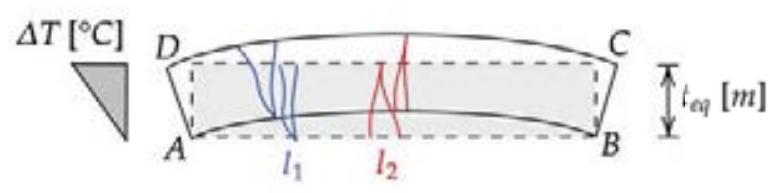

Figure 5: kinematic mechanism possibly associated to the crack behaviour.

measured relative displacements higher than $0.1 \mathrm{~mm}$. The identifie values match with the wall

Table 2: Estimate of the equivalent wall thickness associated to the maximum relative displacement measured by the crack monitoring devices.

\begin{tabular}{ccccc} 
Instrument & Max displ. $[\mathrm{mm}]$ & $\alpha\left[{ }^{\circ} \mathrm{C}^{-1}\right]$ & $\Delta \mathrm{T}\left[{ }^{\circ} \mathrm{C}\right]$ & Equiv. Thickness $[\mathrm{m}]$ \\
\hline FP1 & 0.12 & $5 \times 10^{-6}$ & 30 & 0.80 \\
FP4 & 0.29 & $5 \times 10^{-6}$ & 30 & 1.93 \\
FP5 & 0.36 & $5 \times 10^{-6}$ & 30 & 2.40 \\
FP8 & 0.15 & $5 \times 10^{-6}$ & 30 & 1.00 \\
FP9 & 0.24 & $5 \times 10^{-6}$ & 30 & 1.60
\end{tabular}

thicknesses corresponding to the measurement devices and possibly validate the elementary kinematic mechanism assumed in Fig.5.

The simple calculations in the above paragraphs have the sole objective of a crude understanding of the results. The equivalent thickness is not the physical thickness of the wall. Besides, the real thickness of masonry is not constant, since most of the cracks stand in the vaults, which were reinforced and fille with expanded clay during the retrofittin interventions: the thickness of the vaults depends on the collaboration between the structureand the fillin material. For this reason, the authors preferred to check the amounts of the obtained results, which are on average compatible with the actual masonry thicknesses and, consequently, they possibly descend from the sole thermal effects, rather than other phenomena.

\section{Dynamic monitoring}

The section presents the outcomes of long-term dynamic monitoring. The firs part introduces the results of dynamic identificatio in terms of mode shapes, natural frequencies and viscous damping. The following parts collect the natural frequencies and MAC (Modal Assurance Criterion) values identifie from all time-series and relate them to the outdoor environmental parameters: temperature and relative humidity. 


\subsection{Dynamic identification}

The authors developed an automatic processing algorithm, implemented in MATLAB, based on the Stochastic Subspace Identificatio (SSI)-cov method [43, 44, 45, 46, 47]. The method yields an estimate of the modal parameters from the acceleration time-series recorded in operational condition.

A factor $N_{d}=20$ decimates the initial sampling frequency equal to $250 \mathrm{~Hz}$. [37] details the automatic identificatio algorithm.

\section{The dynamics of the nave walls}

The dynamic identificatio of the nave walls returns four stable modes. The authors report the averaged natural frequencies values up to the firs decimal place. The higher decimal places will be discussed in light of long-term monitoring. The firs mode at $2.09 \mathrm{~Hz}$ (Fig.6(a)) interests the displacement of all measurement points in the same direction. The displacement is consistently low in the apse comparing to the nave walls motion: the apse is very rigid compared to other parts of the basilica. The particular mode shape possibly originates from the Cross Laminated Timber (CLT) ceiling, behaving like a rigid diagram which imposes the same displacement to the nave walls summits.

The higher modes affect the bending of the nave walls. The second mode at $3.11 \mathrm{~Hz}$ (Fig.6(b)) mainly regards the change of direction along the vertical: the measurement points by the top of the columns move oppositely to those by the CLT ceiling. Moreover, the phases of the two nave walls are opposite. The third mode at $3.27 \mathrm{~Hz}$ (Fig.6(c)) mainly concerns the change of direction of the measurement points along the $\mathrm{x}$-direction, like a second bending mode. The fourth mode at $3.82 \mathrm{~Hz}$ (Fig.6(d)) is quite twisted: it is a sort of third bending mode shape. Tab.3 reports the cross MAC between the identifie modes in Fig.6. The terms out of the main diagonal are shallow: the mode shapes are dissimilar between each other and distinctly identifiable

The apse is quite massive, and participate to the identifie mode shapes with much lower defor-

Table 3: Cross MAC between the identifie mode shapes.

\begin{tabular}{c|cccc} 
& 2.09 & 3.11 & 3.27 & 3.82 \\
\hline 2.09 & $\mathbf{1}$ & 0.04 & 0.009 & 0.004 \\
3.11 & 0.04 & $\mathbf{1}$ & 0.006 & 0.004 \\
3.27 & 0.009 & 0.006 & $\mathbf{1}$ & 0.151 \\
3.82 & 0.004 & 0.004 & 0.151 & $\mathbf{1}$
\end{tabular}

mation than the other structural members due to its significan stiffness. The investigation of the apse dynamics requires dedicated efforts and will be the object of future studies by the authors. The dynamic identificatio carried out before the restoration by [31] evidenced four modes (see

Table 4: Evolution of the natural frequencies, before and after the 2009 earthquake and, after the restoration.

\begin{tabular}{ccc} 
& Before 2009 [31] & Since 2017 \\
\hline 1st mode $[\mathrm{Hz}]$ & 1.25 & 2.09 \\
2nd mode $[\mathrm{Hz}]$ & 1.72 & 3.11 \\
3rd mode $[\mathrm{Hz}]$ & 2.35 & 3.27 \\
4th mode $[\mathrm{Hz}]$ & 2.44 & 3.82
\end{tabular}

Tab.4), resembling the ones in Fig.6 with the following natural frequencies: 1.25, 1.72, 2.35 


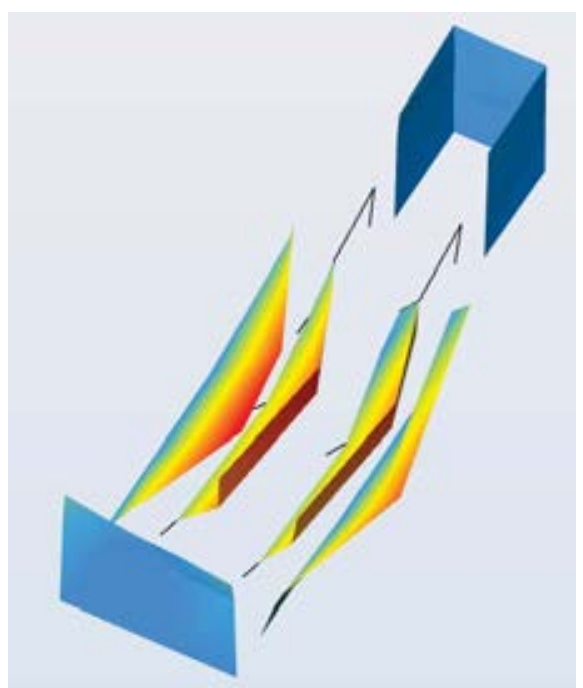

(a) 1 st $\mathrm{m} \cdot 2 \cdot 1 \mathrm{~Hz} \xi \approx 1.25 \%$

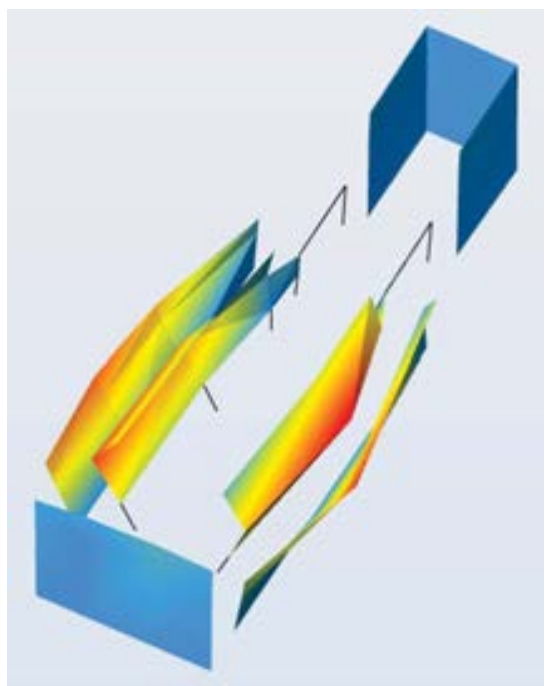

(b) 2 nd m. $3.1 \mathrm{~Hz} \xi \approx 1.19 \%$

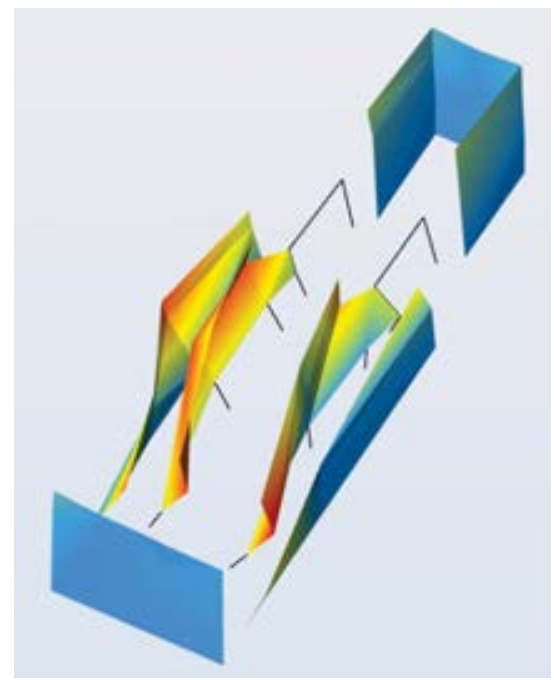

(c) $3 \mathrm{rd} \mathrm{m} \cdot 3.3 \mathrm{~Hz} \xi \approx 1.10 \%$

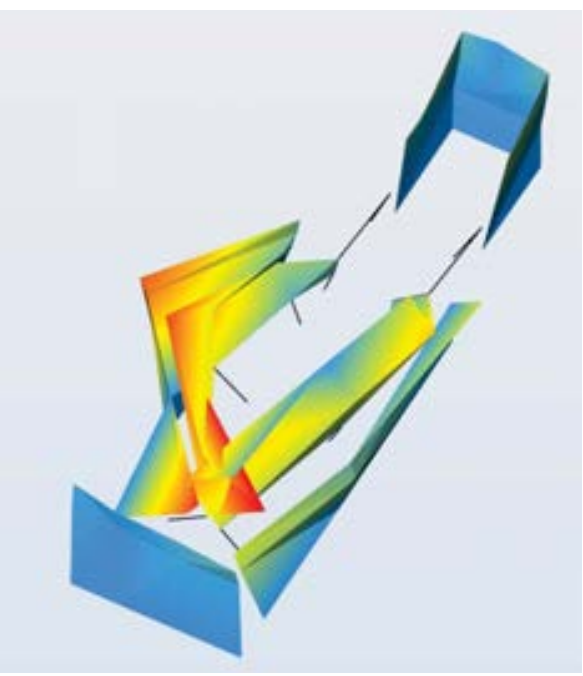

(d) 4 th $\mathrm{m} \cdot 3.8 \mathrm{~Hz} \xi \approx 1.27 \%$

Figure 6: Illustration of the mode shapes of the nave walls, where m. stands for mode and $\xi$ is the average modal damping. 
and $2.44 \mathrm{~Hz}$. The structural interventions following the 2009 earthquake produced meaningful differences on the corresponding natural frequencies, which have increased of $66.80 \%, 80.99 \%$, $39.15 \%$ and $59.35 \%$ respectively; the average increment of the current four natural frequencies is approximately $60.82 \%$, compared to the structural behaviour before the 2009 earthquake. The identificatio in operational condition, based on the current measurement set-up, marks a significan localization in the mode shapes, i.e. many mode shapes show significantl higher displacement in some parts rather than in others. As illustrated in Fig.6, the modes between the 1st and the 4th $(2.1-3.8 \mathrm{~Hz})$ affect almost exclusively nave walls. Although the basilica can be considered as an elastic continuum, the localization of deformation produce the potential uncoupling of the macroelements responses, which are the facade and the nave walls. The localization of deformation might encourage the implementation of predictive reduced-order models for the facade and the nave walls.

\subsection{Long-term monitoring}

The natural frequencies identifie from each set of time-series are concatenated and reported in Fig.7. Tab.7 evidences two concurring trends: the natural frequency oscillates between seasons; The natural frequencies are lightly decreasing in the entire period. The firs observation is in full line with the finding by $[4,10,7,48]$ : the environmental parameters sensibly affect the natural frequencies. However, to the authors' knowledge, the second aspect does not occur in any case study. Tab.6 shows the maximum and minimum values of the linear correlation
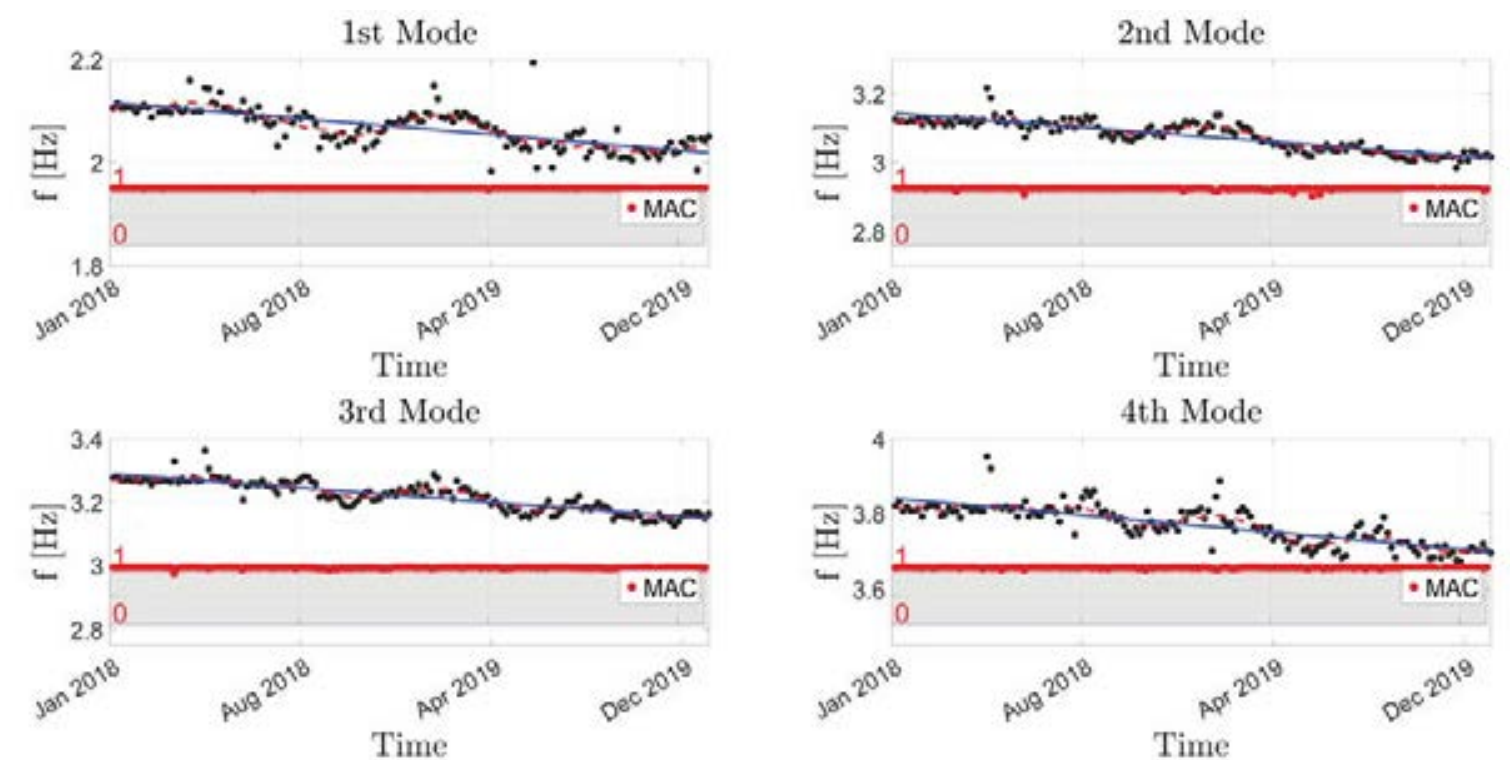

Figure 7: Variation of the natural frequencies and MAC of the detected modes during the investigated period. Red dashed line represents the moving mean of the samples, reflectin frequencies seasonal variation, blue straight interpolating line indicates its general decrease over time. The MAC values refer to a fi ed set of modes corresponding to the recordings of $1 / 1 / 18$.

reported as a solid line in Fig.7. The natural frequencies of the nave walls exhibited a $0.1 \mathrm{~Hz}$ decrement. There are no detectable variations of the mode shapes: the MAC values, estimated to a reference set of mode shapes, stand approximately constant and close to 1, see Fig.7. The nave walls, which are bound together by the top CLT roof, are anchored to the nave walls and the facade by threaded steel bars.

The reason of this decrement may derive from the behaviour exhibited by the constituent mate- 
Table 5: Statistical description of the frequency and MAC values.

\begin{tabular}{ccccc} 
Mode & \multicolumn{2}{c}{ Frequency $[\mathrm{Hz}]$} & \multicolumn{2}{c}{ MAC } \\
& Mean & Variance & Mean & Variance \\
\hline 1st & 2.07 & 0.002 & 0.99 & $5.793 \times 10^{-4}$ \\
2nd & 3.08 & 0.002 & 0.99 & $4.408 \times 10^{-4}$ \\
3rd & 3.22 & 0.002 & 0.99 & $1.502 \times 10^{-4}$ \\
4th & 3.77 & 0.002 & 0.99 & $1.046 \times 10^{-4}$
\end{tabular}

Table 6: Decrease of the natural frequency according to the linear regressions in Fig.7.

\begin{tabular}{cccc} 
Mode & $f_{\text {in }}[H z]$ & $f_{\text {fin }}[\mathrm{Hz}]$ & $\Delta f$ \\
\hline 1st & 2.12 & 2.02 & -0.10 \\
2nd & 3.14 & 3.01 & -0.13 \\
3rd & 3.29 & 3.15 & -0.14 \\
4th & 3.84 & 3.69 & -0.15
\end{tabular}

rials over time. While masonry and steel do not exhibit a sensible decaying of their mechanical properties (especially in two years), it is more likely that the mechanical properties of the CrossLam Timber (CLT) roof are stabilizing. In the authors' opinion, the effect which may justify the observed phenomenonis microcracking due to wood drying and thermal expansion constrained by the steel anchoring [49].

\subsection{Environmental effects}

The natural frequencies are correlated to the outdoor temperature and the relative humidity. As already noticed in the long-term static monitoring, the relative humidity does not yield significan correlations, see Fig.9. Conversely, the temperature values return good correlations, evidenced by the linear fittin in Fig.8.
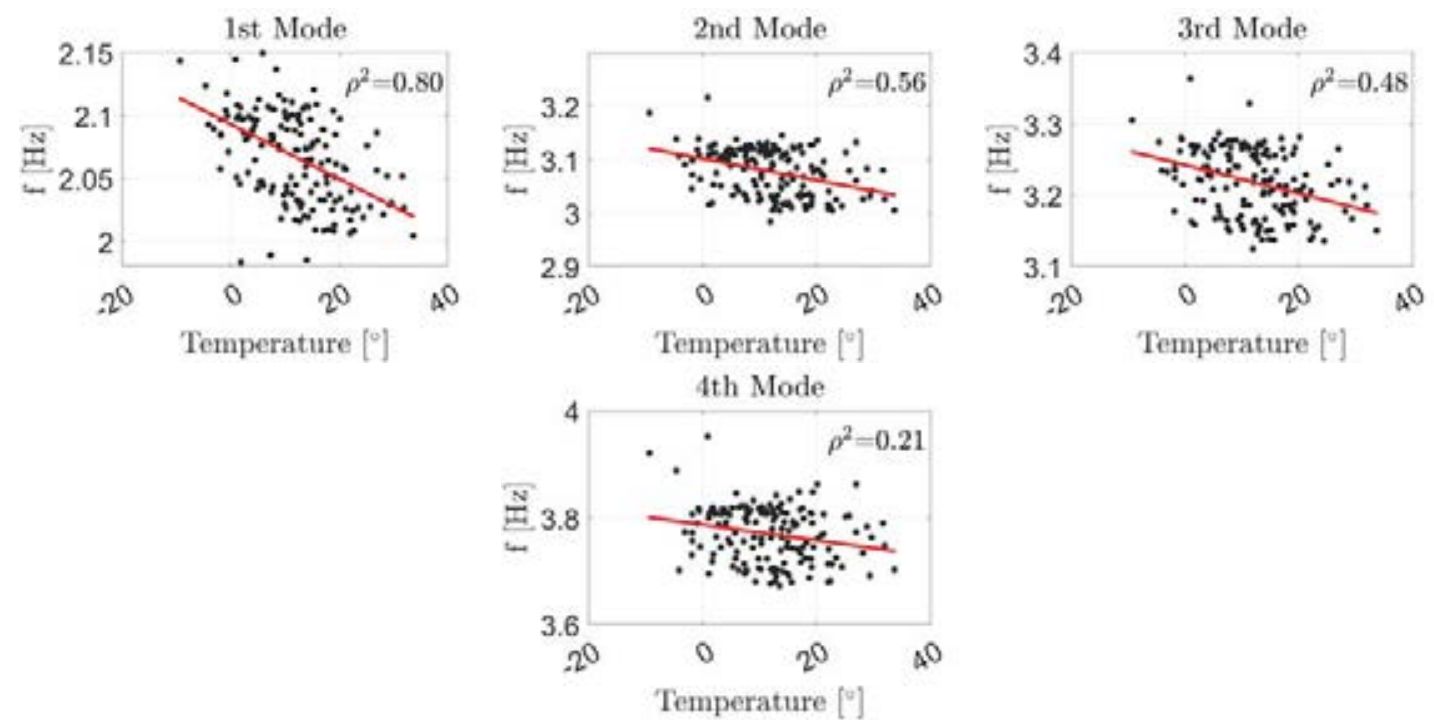

Figure 8: Correlation between the natural frequencies of the identifie modes and the outdoor temperature (from $1 / 01 / 2018$ to $31 / 12 / 2019$ ).

To the authors' knowledge, the negative dependence of the natural frequencies to the outdoor temperature was observed in two sole cases: the Milan cathedral [12] and the Consoli Palace 
in Gubbio [8]. According to Gentile et al. [12], the negative frequency-temperature correlation in the Milan Cathedral originates from the structural arrangement, consisting of double vault system constrained by an extended net of metallic tie-rods.

Kita et al. noticed a negative correlation [8] between natural frequencies and temperature in the Consoli Palace. The marked increase in natural frequencies of the global vibration modes of the Palace with decreasing ambient temperature has been attributed to an increase in global structural stiffness due to strengthening effects of metallic reinforcements (tie rods shortening at lower temperatures) and the presence of a moderate structural damage state in the Palace.

In the current case, the Santa Maria di Collemaggio basilica has a CLT roof which likely experiences significan thermal expansions and contractions. It acts bonding together the nave walls and provides a significan in-plane stiffness to the roof. The negative frequency-temperature correlations could originate from a decrease in global structural stiffness due to the expansion of the CLT roof at higher temperatures.
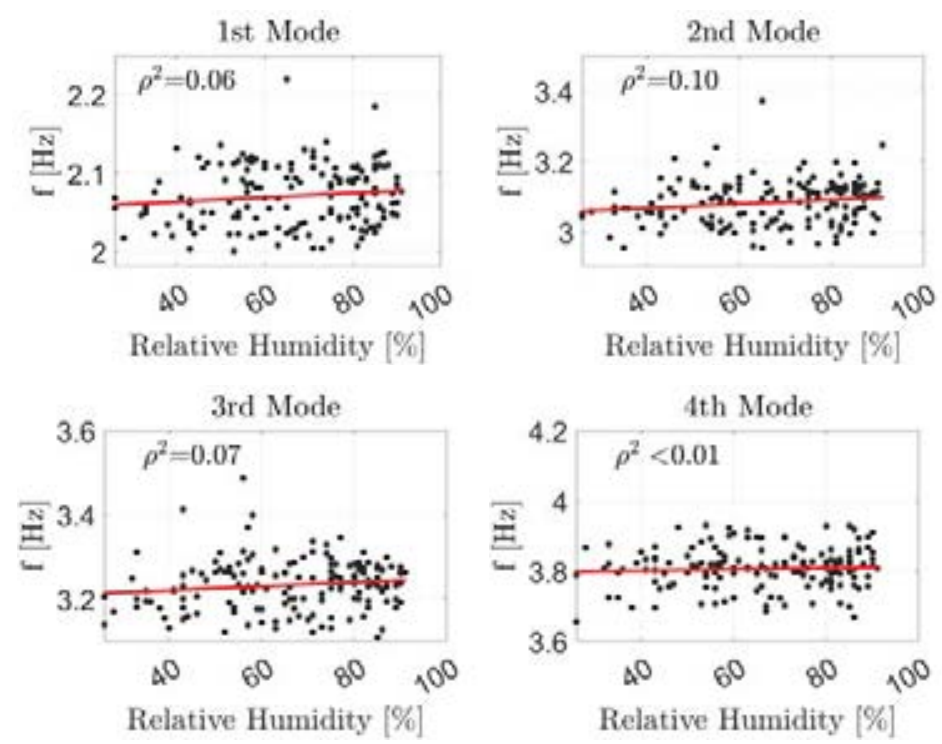

(a)

Figure 9: Correlation between the natural frequencies of the identifie modes and the outdoor Relative Humidity (from $1 / 01 / 2018$ to $31 / 12 / 2019$ ).

The authors further estimated the temperature effects on the mode shapes. Accurately, the cross MAC between the mode shapes identif ed from all recordings are related to the outdoor temperature, as illustrated in Fig.10. The inspection of Fig.10 proves the substantial time invariance of the mode shapes. The crack amplitude was not correlated to the natural frequencies. The sole cracks on the nave walls do not change significantl, see Fig.2. The other cracks mainly gather in the apse and the vaults chapels, which, as remarked, participate with lower deformation to the monitored mode shapes.

\subsection{Discussion}

The most significan result regards the moderate but continuous decay of the natural frequencies over time. Likely, the observed decay will converge towards a stationary value, although the experimental data acquired so far are insufficien to formulate a reliable forecast. Data collected during the years will gradually enhance the reliability of the forecast and allow thoughtful 

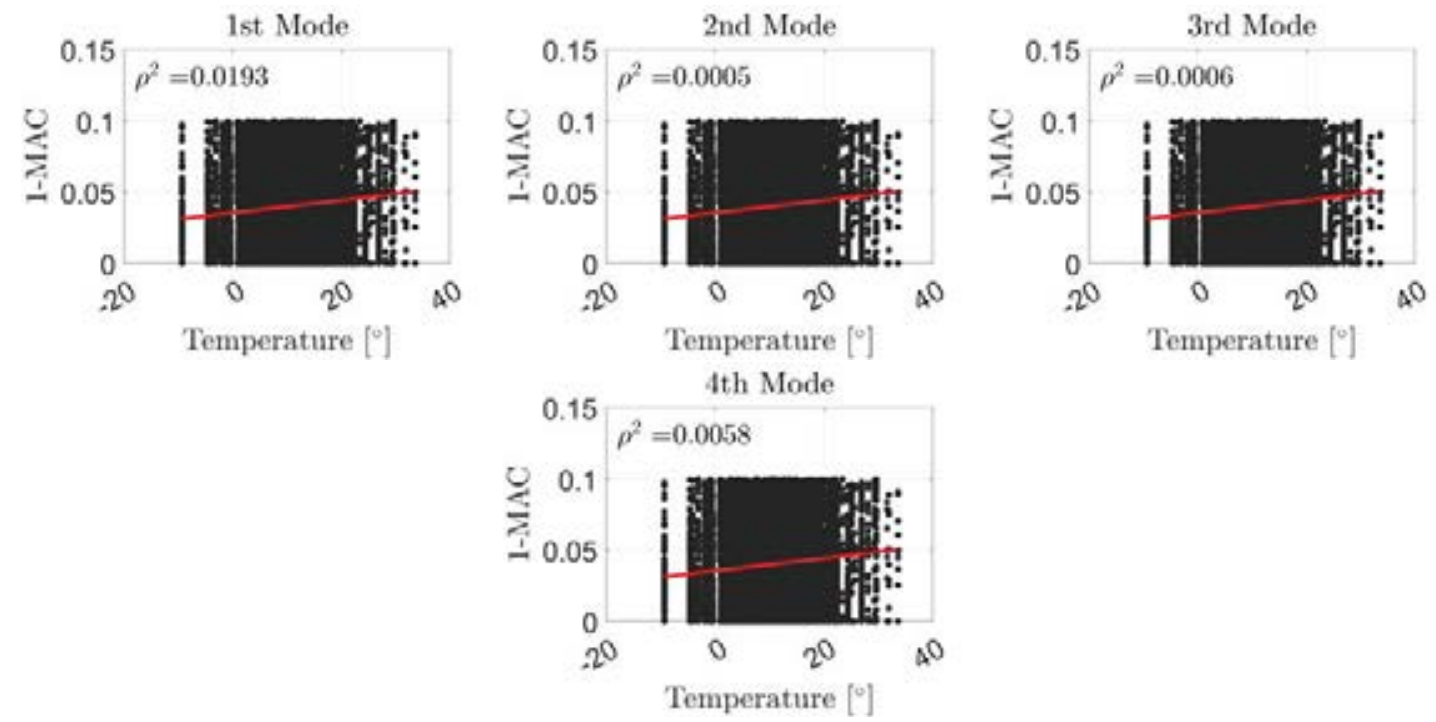

Figure 10: Correlation between outdoor temperature and (1-MAC) of identifie modes (from 1/01/2018 to $31 / 12 / 2019)$.

judgment.

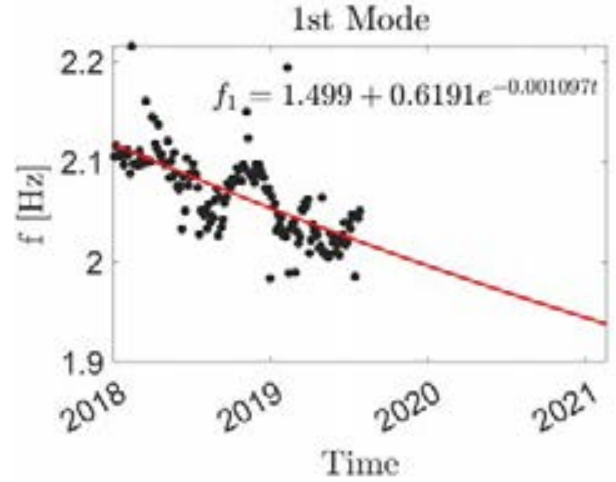

(a)

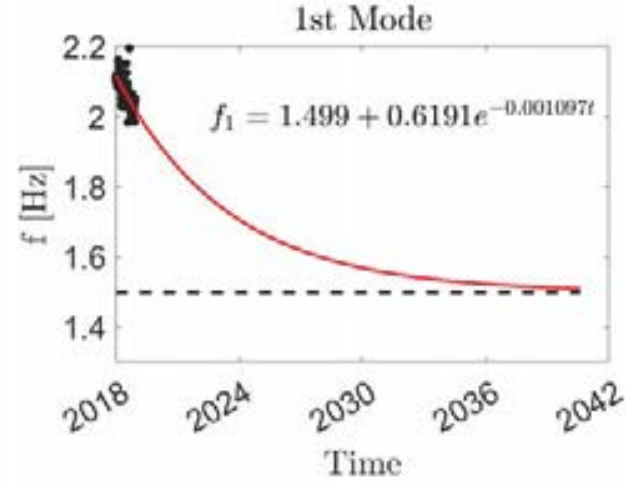

(b)

Figure 11: (a) Detail of the exponential fittin of the firs natural frequency; (b) Exponential fittin of the firs natural frequency extrapolated to a 24 years period.

The authors estimated the optimum exponential fittin of the firs natural frequency using the Lovemberg-Marquardtalgorithm [50], see (Fig.11):

$$
f_{1}=1.499+0.6191 e^{-0.001097 t}
$$

The sole material, among those used in the restoration, which has time-dependent mechanical properties in the firs life period is timber $[51,52,53]$. The mechanical properties of the CLT roof may be stabilizing due to the actual environmental conditions: the CLT roof was installed in 2017. The considered two-years period is too short to derive plausible convergence values. The analysis has a qualitative and illustrative character, aiming at explaining the possible future scenarios. The reported exponential decay suggests that this effect will extinguish in an almost 20 years period since the CLT installation in 2017. 
However, a mechanical interpretation of the obtained results requires a numerical model of the basilica, which allows determining the possible percentage decrease of the CLT roof stiffness congruous with the experimental $f$ ndings. Further, additional instrumentationof the roof would enlighten on the structural behaviour of the timber members.

\section{The dynamics of the facade}

\subsection{Modal identification and long-term monitoring}

The fifth sixth and seventh modes mainly involve the facade, rather than the nave walls (Fig.12). They are all characterized by out-of-plane displacements most visible in the upper part, free, at their rear, from the nave walls constraints.

The fift mode, at $4.5 \mathrm{~Hz}$ (Fig.12(a)), shows the bending of the facade by the rose window, while the modal components given by the sensors at the top edges have the same directions.

The sixth mode at $4.8 \mathrm{~Hz}$ highlights the phase opposition of the displacement of the two upper edges of the facade and a deflectio above the portal (Fig.12(b)).

The last identifie mode is similar to the fifth The main difference lies in a shallow deflectio occurring by the middle of the facade.

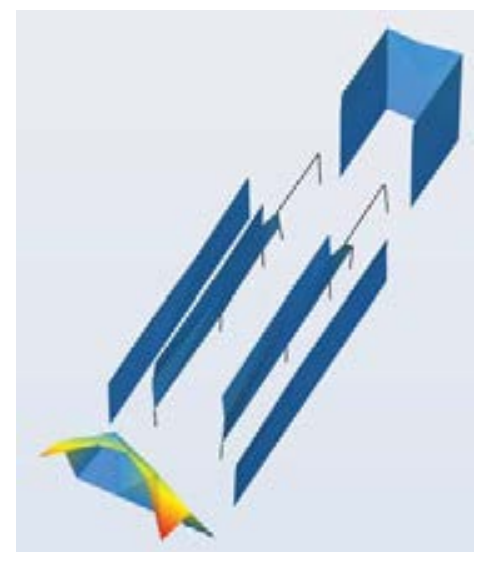

(a) 5 th $\mathrm{m} .4 .5 \mathrm{~Hz} \xi \approx 1.5 \%$

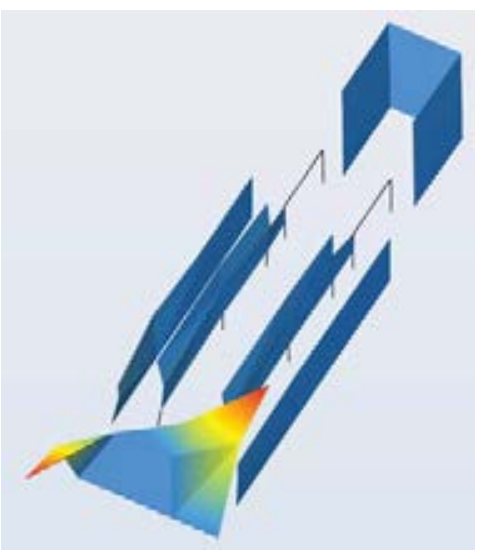

(b) 6 th $\mathrm{m} .4 .8 \mathrm{~Hz} \xi \approx 0.9 \%$

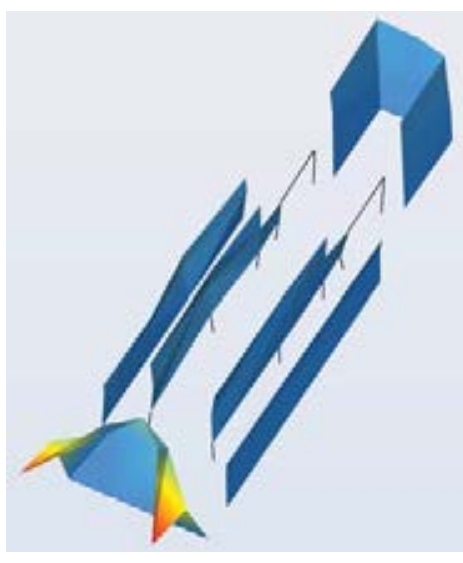

(c) 7 th $\mathrm{m} .5 .2 \mathrm{~Hz} \xi \approx 0.9 \%$

Figure 12: Illustration of the facade mode shapes, where $\mathrm{m}$. stands for mode and $\xi$ is the averaged modal damping.

Fig. 13 presents the results of the modal tracking of the modes associated with the facade. The authors found the same trends found in the previous modes: the seasonal fluctuation of frequencies and their slight decreasing over time. However, the seasonal fluctuation are more marked than those in the previous modes.

Tab. 8 shows the maximum and minimum values of the linear correlation reported as a solid

Table 7: Statistical description of the frequency and MAC values.

\begin{tabular}{ccccc} 
Mode & \multicolumn{2}{c}{ Frequency [Hz] } & \multicolumn{2}{c}{ MAC } \\
& Mean & Variance & Mean & Variance \\
\hline 5th & 4.38 & 0.016 & 0.92 & $6.30 \times 10^{-3}$ \\
6th & 4.78 & 0.018 & 0.94 & $2.63 \times 10^{-3}$ \\
7th & 5.14 & 0.036 & 0.89 & 0.031
\end{tabular}

line in Fig.13. 


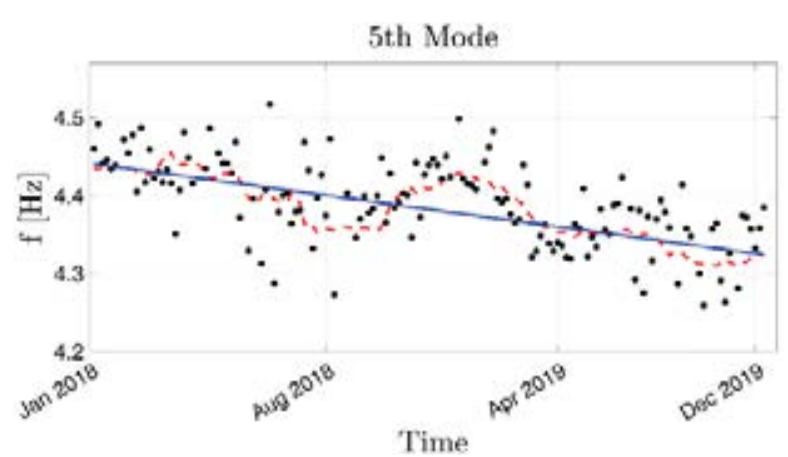

(a) 5 th $\mathrm{m} .4 .5 \mathrm{~Hz} \xi \approx 1.5 \%$

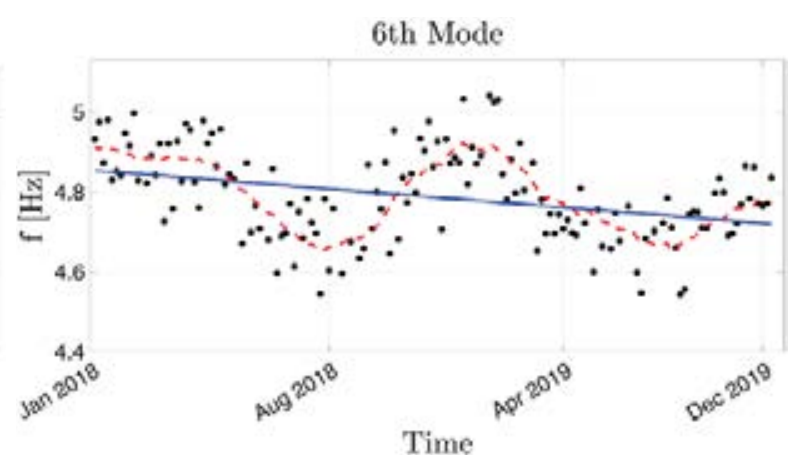

(b) 6 th $\mathrm{m} .4 .8 \mathrm{~Hz} \xi \approx 0.9 \%$

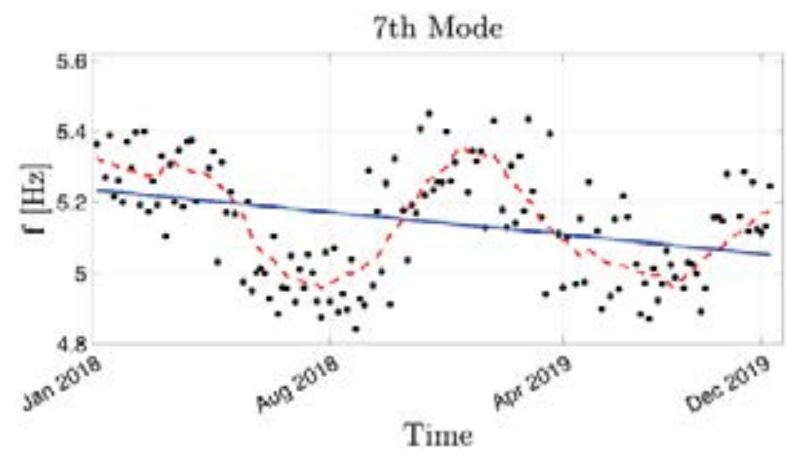

(c) 7 th $\mathrm{m} .5 .2 \mathrm{~Hz} \xi \approx 0.9 \%$

Figure 13: Variation of the natural frequencies during the year. The red dashed line represents the moving mean of the samples, the blue straight interpolating line indicates its general decrease over time.

Table 8: Decrease of the natural frequency according to the linear regressions in Fig.13.

\begin{tabular}{cccc} 
Mode & $f_{\text {in }}[\mathrm{Hz}]$ & $f_{\text {fin }}[\mathrm{Hz}]$ & $\Delta f$ \\
\hline 5th & 4.44 & 4.32 & -0.12 \\
6th & 3.14 & 3.01 & -0.13 \\
7th & 3.29 & 3.15 & -0.18
\end{tabular}




\subsection{Modal interaction}

An impressive phenomenon affects the fift and seventh modes: not solely their natural frequencies decrease during the hot season, but their shape and the mutual distance between the frequencies do change during the year, almost cyclically in both the years under investigation. In order to better understand what happens, dates belonging to two different seasons have been compared: as evidenced by Tab.9, the frequencies vary between $3 \%$ and $8 \%$ among January and September.

The MAC between modal shapes proves a similarity between the 5th mode of September and

Table 9: The identifie frequencies in January and September, 2019.

\begin{tabular}{cccc} 
Mode & Jan & Sept & $\Delta \mathrm{f}(\%)$ \\
\hline 5th & 4.43 & 4.28 & -3.3 \\
6th & 4.82 & 4.43 & -8.0 \\
7th & 5.14 & 4.85 & -5.6
\end{tabular}

the 7 th mode of January and vice versa (Tab.10). The sixth mode does not seem to be affected by changes in shape.

Fig.14 shows the one-year variations of the 5 th and 7 th natural frequencies, adimensionalized

Table 10: MAC evaluated between the modes of the facade identifie in January and in September, 2019.

\begin{tabular}{cccc} 
Mode & $5 t h_{\text {Jan }}$ & $6 t h_{\text {Jan }}$ & $7 t h_{\text {Jan }}$ \\
\hline $5 t h_{\text {Sept }}$ & 0.685 & 0.002 & $\mathbf{0 . 9 0 1}$ \\
$6 t h_{\text {Sept }}$ & 0.130 & $\mathbf{0 . 9 0 5}$ & 0.150 \\
$7 t h_{\text {Sept }}$ & $\mathbf{0 . 6 8 9}$ & 0.266 & 0.567
\end{tabular}

to the fift mode, compared to the temperature values. The increase in temperature, typical of the summer season, leads the frequencies to approach each other.

The mode shapes change during the year: the two mode shapes mutate until reaching the

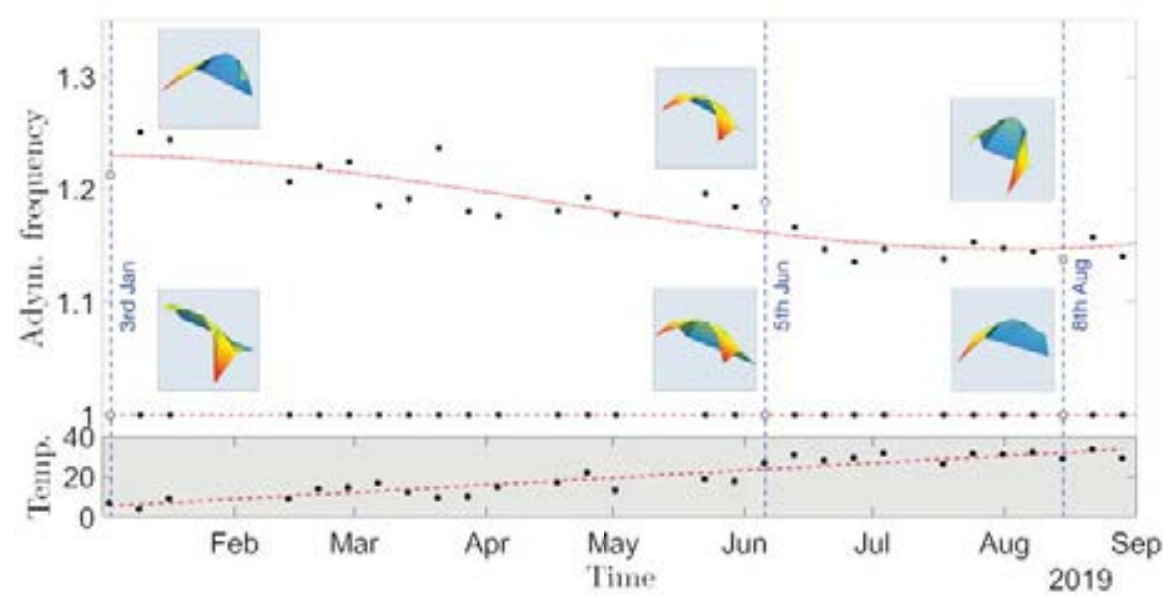

Figure 14: Evolution of the fift and seventh natural frequency, adimensionalized to the fifth The dash-dot line interpolates the data associated with the seventh mode. The pictures of the mode shapes correspond to the dates indicated. Below, the trend of temperatures in the same period. Data correspond to acquisitions recorded at the same hour ( $2 \mathrm{pm}$ ) between January and September, when temperature progressively rises.

maximum similarity in June, and then they exhibit the complete shape inversion between August 
and September, in which temperature attains the highest values.

Subsequently, the arrival of the cold season determines the reversed process: both the mode shapes return to their starting states.

The phenomenon is strongly related to temperature: the variation of the two mode shapes is synthetically described by introducing the $R$ parameter, define as

$$
R=\frac{d_{F 9}}{d_{F 5}}
$$

The parameter represents the ratio between the out-of-plane mode components in points $F 9$, on the left top of the facade, and $F 5$ on the opposite side. Fig. 15 shows the value of the $R$ param-

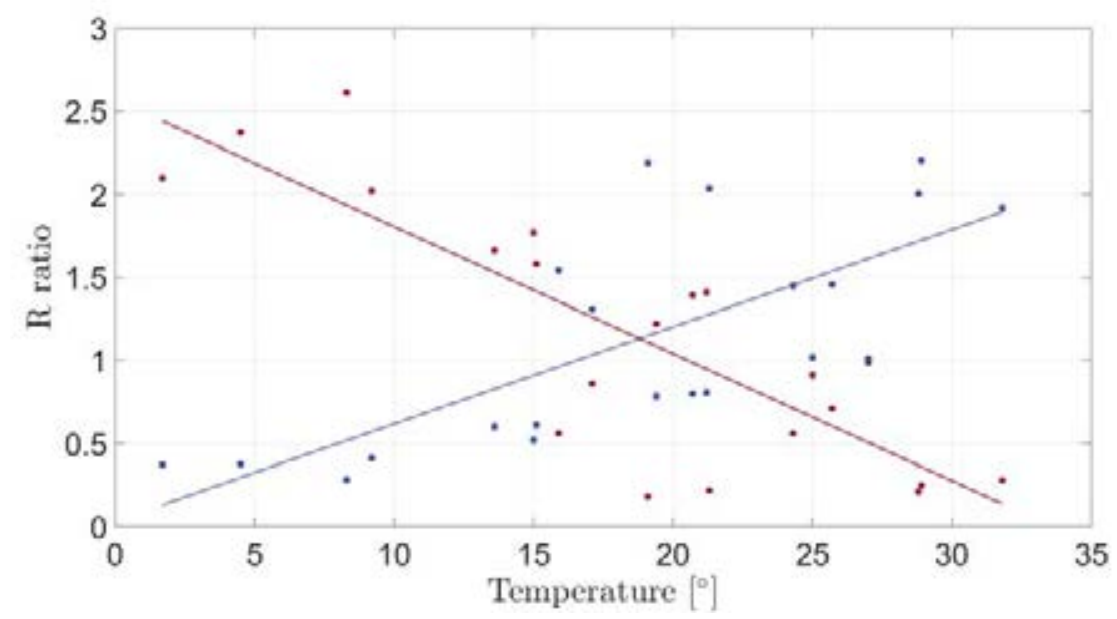

Figure 15: R Ratio evaluated for both the 5th mode (blue) and the 7th (red).

eter associated with the 5 th and the 7 th modes, which have opposite temperature correlations. The intersection of the two interpolating lines identifie a value of $R$ approximately equal to one, meaning that the modal displacements of the two upper edges of the facade coincide, for both modes. The abscissa of the intersection point marks a temperature of about 20 degrees, attributable to that recorded in June.

The trend of frequencies of the 7th mode evidences a slight increase at the end of August, while the temperature still increases.

Although samples recorded in this month are too scarce to yield a sound validation, the overall phenomenon partially resembles that of mode interaction typical of frequency veering, well known in structural dynamics [54].

In the authors' opinion, this particular behaviour could be due to local effects related to the influenc of temperature on the elastic parameters of the structure.

\section{Conclusions}

The paper presents the results of two years (2018-2019) static and dynamic monitoring of the Santa Maria di Collemaggio basilica. The masonry structure, severely damaged by the 2009 earthquake in L'Aquila, was rehabilitated and reopened in 2017. The restoration included the installation of a monitoring system consisting of 78 Force Balance accelerometers and nine crack monitoring devices. The authors mainly focused on the estimate of the modal properties and the effect of the environmental parameters. Here follow the main results of this study: 
1. Seven modes have been detected in the frequency range $0-5.5 \mathrm{~Hz}$, identifie in operational condition using the SSI-cov algorithm [43]. The identification based on the current measurement set-up, denotes a notable localization in the mode shapes, i.e. many mode shapes show significantl higher displacement in some parts rather than in others. The firs four modes $(2.1-3.8 \mathrm{~Hz})$ affect almost exclusively nave walls. Conversely, the following modes $(4.5-5.3 \mathrm{~Hz}$ ) affects the facade and negligibly the nave walls.

2. The authors implemented an automatic algorithm to identify the modal parameters and track their evolution over time. The natural frequencies are decreasing over time: In two years, there has been an almost $0.1 \mathrm{~Hz}$ frequency decrement. It possibly derived from the moderate in-plane stiffness decaying of the Cross Lam timber roof due to superficia microcracking (wood drying and constrained thermal expansion, e.g.).

3. The modal tracking process of the modes mainly affecting the facade evidenced a phenomenon resembling frequency veering and mode interaction. It strongly depends on temperature: the frequencies of the two modes approach to each other with increasing temperature and their shapes interchange cyclically over time. Despite this, the algorithm was able to perform the tracking process. Other mode shapes do not experience meaningful seasonal variations and are substantially time-invariant.

4. The outdoor temperature drives the observed fluctuation of the natural frequencies. The firs four modes have negative temperature-frequenc correlations. This effect could arise from a decrease in the global structural stiffness due to the expansion of the CLT roof at higher temperatures. For modes mainly involving the facade, frequency variation due to temperatureis amplifie by the phenomenonof frequency veering.

5. The outdoor temperature mainly drives the crack evolution. In most cases, the devices revealed positive temperature-amplitudecorrelations. In a single case, the authors noted the opposite trend. The two behaviours possibly originate from the difference between the outdoor and indoor temperature. The thermal gradient enhances the curvature of the wall, yielding stretching or closing of the cracks depending on their position across the wall thickness.

This paper mainly focuses on the dynamic monitoring of the nave walls and the facade. Future developments will deal with the dynamics of the apse and transept. The present analyses are preliminary to the developing of a probabilistic model of the modal response of the basilica within a Structural Health Monitoring program.

\section{Acknowledgments}

The authors thank Eni, for having finance the restoration of the basilica and the monitoring system, Prof. Dante Galeota as Representative of the University of L'Aquila in the restoration committee, Dr Felice Fusco for his contribution in the design phase of the monitoring system, Prof. Roberto Aloisio to be intermediary with the CETEMPS, and the CETEMPS itself, the centre of excellence on telesensing of environment and model prediction severe events (http://cetemps.aquila.infn.it/) of the University of L'Aquila, which provided us with the environmental parameters. The authors further acknowledge the availability of the SolGeo s.r.l. for the maintenance needs. 


\section{REFERENCES}

[1] C. R. Farrar, W. Baker, T. Bell, K. Cone, T. Darling, T. Duffey, A. Eklund, and A. Migliori, "Dynamic characterization and damage detection in the i-40 bridge over the rio grande," tech. rep., Los Alamos National Lab., NM (United States), 1994.

[2] S. Quqa, L. Landi, and P. P. Diotallevi, "Instantaneous modal identificatio under varying structural characteristics: A decentralized algorithm," Mechanical Systems and Signal Processing, vol. 142, p. 106750, 2020.

[3] A. Aloisio, A. Di Pasquale, R. Alaggio, and M. Fragiacomo, "Assessment of seismic retrofittin interventions of a masonry palace using operational modal analysis," International Journal of Architectural Heritage, pp. 1-13, 2020.

[4] L. F. Ramos, L. Marques, P. B. Lourenço, G. De Roeck, A. Campos-Costa, and J. Roque, "Monitoring historical masonry structures with operational modal analysis: two case studies," Mechanical systems and signal processing, vol. 24, no. 5, pp. 1291-1305, 2010.

[5] F. Ubertini, G. Comanducci, N. Cavalagli, A. L. Pisello, A. L. Materazzi, and F. Cotana, "Environmental effects on natural frequencies of the san pietro bell tower in perugia, italy, and their removal for structural performance assess ment," Mechanical Systems and Signal Processing, vol. 82, pp. 307-322, 2017.

[6] A. Saisi, C. Gentile, and M. Guidobaldi, "Post-earthquake continuous dynamic monitoring of the gabbia tower in mantua, italy," Construction and Building Materials, vol. 81, pp. 101-112, 2015.

[7] R. M. Azzara, G. De Roeck, M. Girardi, C. Padovani, D. Pellegrini, and E. Reynders, “The influenc of environmental parameters on the dynamic behaviour of the san frediano bell tower in lucca," Engineering Structures, vol. 156, pp. 175-187, 2018.

[8] A. Kita, N. Cavalagli, and F. Ubertini, "Temperature effects on static and dynamic behavior of consoli palace in gubbio, italy," Mechanical Systems and Signal Processing, vol. 120, pp. 180-202, 2019.

[9] M.-G. Masciotta, J. C. Roque, L. F. Ramos, and P. B. Lourenço, "A multidisciplinary approach to assess the health state of heritage structures: The case study of the church of monastery of jerónimos in lisbon," Construction and Building Materials, vol. 116, pp. 169-187, 2016.

[10] M.-G. Masciotta, L. F. Ramos, and P. B. Lourenço, “The importance of structural monitoring as a diagnosis and control tool in the restoration process of heritage structures: a case study in portugal," Journal of Cultural Heritage, vol. 27, pp. 36-47, 2017.

[11] A. Elyamani, O. Caselles, P. Roca, and J. Clapes, "Dynamic investigation of a large historical cathedral," Structural Control and Health Monitoring, vol. 24, no. 3, p. e1885, 2017.

[12] C. Gentile, A. Ruccolo, and F. Canali, "Long-term monitoring for the condition-based structural maintenance of the milan cathedral," Construction and Building Materials, vol. 228, p. 117101, 2019. 
[13] M. G. Lopardi, I templari ed il colle magico di Celestino. Idea libri, 2002.

[14] F. Redi, "Santa maria di collemaggio. archeologia di un monumento", Celestino Ve la sua Basilica, pp. 71-133, 2006.

[15] M. Moretti, Collemaggio. De Luca, 1972.

[16] D. Oreni, R. Brumana, S. Della Torre, F. Banfi and M. Previtali, "Survey turnedinto hbim: the restoration and the work involved concerning the basilica di collemaggio after the earthquake (l'aquila)," ISPRS annals of the photogrammetry, remote sensing and spatial information sciences, vol. 2, no. 5, p. 267, 2014.

[17] V. Baiocchi, V. Giammarresi, R. Ialongo, C. Piccaro, M. Allegra, and D. Dominici, "The survey of the basilica di collemaggio in l'aquila with a system of terrestrial imaging and most proven techniques," European Journal of Remote Sensing, vol. 50, no. 1, pp. 237$253,2017$.

[18] R. Brumana, S. Della Torre, M. Previtali, L. Barazzetti, L. Cantini, D. Oreni, and F. Banfi "Generative hbim modelling to embody complexity (lod, log, loa, loi): surveying, preservation, site intervention-the basilica di collemaggio (l'aquila)," Applied geomatics, vol. 10, no. 4, pp. 545-567, 2018.

[19] E. Antonacci, G. Beolchini, and F. D. F. V. Gattulli, "Retrofittin effects on the dynamic behaviour of s. maria di collemaggio," WIT Transactions on Modelling and Simulation, vol. 30, 2001.

[20] D. Ranalli, M. Scozzaf ava, and M. Tallini, "Ground penetrating radar investigations for the restoration of historic buildings: the case study of the collemaggio basilica (l'aquila, italy)," Journal of cultural heritage, vol. 5, no. 1, pp. 91-99, 2004.

[21] E. Antonacci, V. Gattulli, A. Martinelli, and F. Vestroni, "Il crollo del transetto della basilica di collemaggio: analisi di vulnerabilita'e meccanismo di collasso," in Atti del workshop: Sicurezza e conservazione dei beni culturali colpiti da sisma: Strategie e tecniche di ricostruzione ad un anno dal terremoto abruzzese, pp. 8-9, 2010.

[22] S. Sfarra, A. Bendada, C. Ibarra-Castanedo, D. Ambrosini, D. Paoletti, and X. Maldague, "Santa maria di collemaggio church (l'aquila, italy): historical reconstruction by nondestructive testing techniques," International Journal of Architectural Heritage, vol. 9, no. 4, pp. 367-390, 2015.

[23] P. Crespi, A. Franchi, N. Giordano, M. Scamardo, and P. Ronca, "Structural analysis of stone masonry columns of the basilica s. maria di collemaggio," Engineering structures, vol. 129, pp. 81-90, 2016.

[24] M. Zucca, A. Franchi, P. Crespi, N. Longarini, and P. Ronca, “The new foundation system for the transept reconstruction of the basilica di collemaggio," in 10th IMC-Proceedings of the 10th International Masonry Conference, pp. 2441-2450, 2018.

[25] A. Aloisio, R. Alaggio, and M. Fragiacomo, "Dynamic identificatio of a masonry façade from seismic response data based on an elementary ordinary least squares approach," Engineering Structures, vol. 197, p. 109415, 2019. 
[26] E. Antonacci, A. Aloisio, D. Galeota, and R. Alaggio, "The s. maria di collemaggio basilica: from vulnerability assessment to firs results of shm," Journal of Architectural Engineering, vol. In press, 2020.

[27] A. Aloisio, L. Di Battista, R. Alaggio, and M. Fragiacomo, "Analysis of the forced dynamics of a masonry facade by means of input-outputtechniques and a linear regression model," in COMPDYN, 2019, 7th International Conference on Computational Methods in Structural Dynamics and Earthquake Engineering, 2019.

[28] S. Amoroso, I. Gaudiosi, M. Tallini, G. Di Giulio, and G. Milana, "2d site response analysis of a cultural heritage: the case study of the site of santa maria di collemaggio basilica (l'aquila, italy)," Bulletin of Earthquake Engineering, vol. 16, no. 10, pp. 4443-4466, 2018.

[29] G. Totani, P. Monaco, F. Totani, G. Lanzo, A. Pagliaroli, S. Amoroso, and D. Marchetti, "Site characterization and seismic response analysis in the area of collemaggio, l'aquila (italy)," in Proc., 5th International Conf on Geotechnical and Geophysical Site Characterization, Australian Geomechanics Society, Gold Coast, Australia, vol. 2, pp. 1051-1056, 2016.

[30] N. Aste, S. Della Torre, R. S. Adhikari, M. Buzzetti, C. Del Pero, F. Leonforte, and M. Manfren, "Sustainable church heating: The basilica di collemaggio case-study," Energy and Buildings, vol. 116, pp. 218-231, 2016.

[31] E. Antonacci, G. Beolchini, F. Di Fabio, and V. Gattulli, "The dynamic behaviour of the basilica s. maria di collemaggio," in Proc. of 2 nd Int. Congress on Studies in Ancient Structures, SAS2001, 2001.

[32] E. Antonacci and G. Beolchini, "The dynamic behaviour of the façade of the basilica s. maria di collemaggio," Structural analysis of historical constructions, pp. 469-476, 2005.

[33] F. Potenza, F. Federici, M. Lepidi, V. Gattulli, F. Graziosi, and A. Colarieti, "Long-term structural monitoring of the damaged basilica s. maria di collemaggio through a low-cost wireless sensor network," Journal of Civil Structural Health Monitoring, vol. 5, no. 5, pp. 655-676, 2015.

[34] D. Galeota, G. Sforza, and L. Sbaraglia, "Dynamic characterization of the basilica of s. maria di collemaggio after the earthquake of 2009 by means of operational modal analysis," Computational Methods and Experimental Measurements XVII, vol. 59, p. 357, 2015.

[35] D. Galeota, E. Antonacci, A. Aloisio, and R. Alaggio, "The s. maria di collemaggio basilica: from the vulnerability assessment to the firs results of shm," in Proceedings of the XVII National Conference ANIDIS, 13-17 September 2019, Ascoli Piceno, Italy, vol. 17, ANIDIS, 2019.

[36] A. Aloisio, E. Antonacci, M. Fragiacomo, and R. Alaggio, "The recorded seismic response of the santa maria di collemaggio basilica to low-intensity earthquakes," International Journal of Architectural Heritage, 2020. 
[37] R. Alaggio, A. Aloisio, E. Antonacci, and R. Cirella, "Two-years static and dynamic monitoring of the santa maria di collemaggio basilica," Construction and Building Materials, p. $121069,2020$.

[38] C. Bartolomucci, Santa Maria di Collemaggio: interpretazione critica e problemi di conservazione. Palombi, 2004.

[39] M. Angiolilli, A. Gregori, M. Pathirage, and G. Cusatis, "Fiber reinforced cementitious matrix (frcm) for strengtheninghistorical stone masonry structures: Experiments and computations," Engineering Structures, vol. 224, p. 111102, 2020.

[40] A. Aloisio, M. Fragiacomo, and G. D’Al ò, “Traditional tf masonries in the city centre of l'aquila-the baraccato aquilano," International Journal of Architectural Heritage, pp. 1$18,2019$.

[41] A. Aloisio, M. Fragiacomo, and G. D'Al ò, “The 18th-century baraccato of l'aquila," International Journal of Architectural Heritage, pp. 1-15, 2019.

[42] A. Aloisio, I. Capanna, R. Cirella, R. Alaggio, and M. Fragiacomo, "The san silvestro belfry: dynamic identificatio and model updating via numerical and analytical modelling," Buildings, 2020.

[43] B. Peeters and G. De Roeck, "Reference-based stochastic subspace identificatio for output-only modal analysis," Mechanical systems and signal processing, vol. 13, no. 6, pp. 855-878, 1999.

[44] A. Aloisio, D. Pasca, R. Tomasi, and M. Fragiacomo, "Dynamic identificatio and model updating of an eight-storey clt building," Engineering Structures, vol. 213, p. 110593, 2020.

[45] A. Aloisio, L. Di Battista, R. Alaggio, and M. Fragiacomo, "Sensitivity analysis of subspace-based damage indicators under changes in ambient excitation covariance, severity and location of damage," Engineering Structures, vol. 208, p. 110235, 2020.

[46] A. Aloisio, R. Alaggio, and M. Fragiacomo, "Time-domain identificatio of elastic modulus of simply supported box girders under moving loads: method and full-scale validation," Engineering Structures, 2020.

[47] A. Aloisio, R. Alaggio, and M. Fragiacomo, "Dynamic identificatio and model updating of full-scale concrete box girders based on the experimental torsional response," Construction and Building Materials, vol. 264, p. 120146, 2020.

[48] C. Gentile and A. Saisi, "Ambient vibration testing of historic masonry towers for structural identificatio and damage assessment," Construction and building materials, vol. 21, no. 6, pp. 1311-1321, 2007.

[49] M. Piazza, R. Modena, and R. Tomasi, Strutture in legno. Materiale, calcolo e progetto secondo le nuove normative europee. Hoepli Editore, 2005.

[50] J. J. Moré, “The levenberg-marquardtalgorithm: implementation and theory," in Numerical analysis, pp. 105-116, Springer, 1978. 
[51] Z. Chen, C. Ni, C. Dagenais, and S. Kuan, "Woodst: a temperature-dependentplasticdamage constitutive model used for numerical simulation of wood-based materials and connections," Journal of Structural Engineering, vol. 146, no. 3, p. 04019225, 2020.

[52] A. Aloisio, R. Alaggio, and M. Fragiacomo, "Equivalent viscous damping of crosslaminated timber structural archetypes," Journal of Structural Engineering, vol. 147, no. 4, p. 04021012, 2021.

[53] A. Aloisio, R. Alaggio, and M. Fragiacomo, "Fragility functions and behavior factors estimation of multi-story cross-laminated timber structures characterized by an energydependenthysteretic model," Earthquake Spectra, p. 8755293020936696, 2020.

[54] F. Benedettini, D. Zulli, and R. Alaggio, "Frequency-veering and mode hybridization in arch bridges," in Proceedings of the 27th International Modal Analysis Conference, 2009. 